\title{
Prognosis of Chronic Subdural Hematoma using Noninvasive Skull Impedance Plethysmography
}

\author{
Totaro TAKEUCHI, Takashi TsuboKAWA*, Nariyuki HAYASHI*, \\ Hidehiko KUSHI* and Shin KIMURA*
}

\author{
Neurosurgical Department, The Municipal of Higashimatsuyama Hospital, \\ Higashimatsuyama, Saitama; \\ *Department of Neurological Surgery, Nihon University, School of Medicine, Tokyo
}

\begin{abstract}
Postoperative resolution of neurological symptoms was assessed in eight patients with chronic subdural hematoma by means of noninvasive skull impedance plethysmography. A control population comprising 20 normal adults was also studied. Preoperatively, in comparison with the control subjects, the patients with chronic subdural hematoma had much higher intracranial pressure, considerably reduced mean cerebral blood flow, greater cerebrovascular resistance, a longer cerebrovascular conduction time, and somewhat lower cerebrovascular compliance and cerebral perfusion pressure. The differences in the last five parameters reflect pathophysiological changes due to elevated intracranial pressure in the hematoma patients. Among those who showed neurological improvement after surgery, the most dramatic changes, as demonstrated by a 5 -minute $3 \% \mathrm{CO}_{2}$ inhalation test, were mean increases in mean cerebral blood flow of $106.7 \%$ and in cerebrovascular compliance of $101.5 \%$. Among the patients who responded poorly to surgery, the corresponding mean increases were only $44.5 \%$ and $46.5 \%$, respectively.
\end{abstract}

Key words: intracranial pressure, cerebral blood flow, skull impedance plethysmography, chronic subdural hematoma

\section{Introduction}

In chronic subdural hematoma, persistence of the clot induces symptoms of secondary cerebral compression through a variety of pathophysiological changes, including cerebral edema and alterations in cerebrovascular reactivity. These events then increase cerebral blood and cerebrospinal fluid volumes and, finally, reduce cerebral blood flow or induce cerebral herniation. In attempts to predict the outcome of surgery for chronic subdural hematoma, various methods, including computed tomography (CT), have been employed to determine of the extent of cerebral atrophy,,$^{6,17-19,24)}$ hematoma density, hematoma configuration, ${ }^{13.19 .20}$ and cerebrovascular compliance. ${ }^{24)}$ In the present study, we evaluated the usefulness of the previously reported method of noninvasive skull impedance plethysmography ${ }^{10,11,22)}$ in predicting the clinical effectiveness of

Received March 23, 1987; Accepted December 9, 1987 surgery in these patients. We measured such factors as intracranial pressure (ICP), mean cerebral blood flow (mCBF), cerebrovascular resistance (CVR), and cerebrovascular compliance (CVC).

\section{Subjects and Methods}

\section{Subjects}

The patient population comprised seven males and one female with chronic subdural hematoma who were awaiting irrigation of the hematoma. Their mean age was 70.8 years. The hematoma was on the left side in five cases and on the right in three. Skull impedance plethysmography was performed both preoperatively and postoperatively; ICP, cerebral perfusion pressure (CPP), CVR, CVC, cerebrovascular conduction time ( $\mathrm{CVCT}$ ), and $\mathrm{mCBF}$ were estimated. Reactivity to 5-minute inhalation of 3\% $\mathrm{CO}_{2}$ was also studied. Surgery was considered "effective" or "ineffective" according to whether or not a patient showed improvement in neurological symptoms due to brain compression (e.g., hemipare- 
sis or mental symptoms) within 1 month postoperatively.

Skull impedance plethysmography was also performed in 20 normal, elderly adults ( 16 males and four females with a mean age of 66.5 years). ICP, CPP, CVR, CVC, CVCT, and $\mathrm{mCBF}$ were measured.

\section{Theory and technique of noninvasive skull impedance plethysmography}

The brain, suspended in the cerebrospinal fluid and anchored by nerves and blood vessels, produces pressure waves whose complex forms reflect changes in the cerebral blood volume. These changes result from two distinct vascular rhythms, i.e., that which is synchronous with the heartbeat, and that which corresponds to the relatively slower respiratory function. ${ }^{4)}$ If the cerebral blood volume fluctuations as a function of brain movement can be measured extracranially, then ICP can be calculated from the equation given below. This equation is based on data from skull impedance plethysmography and epidural pressure monitoring, ${ }^{10,11)}$ both of which have shown that respiratory cerebral movement $(\Delta R)$ decreases as ICP rises, while arterial pulsatile cerebral movement $(\triangle \mathrm{Pa})$ increases.

$$
\mathrm{ICP}=\mathrm{K}_{1}\left(1+\log ^{\Delta \mathrm{Pa}} / \Delta \mathrm{R}\right)-150
$$

where $K_{1}$ is the proportionality coefficient $(=200)$. Furthermore, according to the theories of Geddes and Baker ${ }^{7)}$ and Anderson et al.$^{1,2,12)}$ that the change seen in skull impedance plethysmography $(\Delta \mathrm{V})$ is proportionate to the increase or decrease in cerebral blood volume due to jugular venous occlusion (i.e., occlusion of the cerebral circulation at the venous outlet) for less than 15 seconds (usually 5 seconds) and is not involved in autoregulation, $, 5,8,10,11,21)$ $\mathrm{mCBF}$ can be calculated by the following equation.

$$
\mathrm{mCBF}=\mathrm{K}_{2} \cdot \Delta \mathrm{V} \cdot \mathrm{t} \ldots \ldots \ldots \ldots \ldots \ldots
$$

where $K_{2}$ is the proportionality coefficient $(=500)$ and $\mathrm{t}$ is the time required for $\Delta \mathrm{V}$ to change, being usually 5 seconds. In addition, using the equation $\mathrm{mCBF}=(\mathrm{MABP}-\mathrm{ICP}) / \mathrm{CVR}$, one can determine the CVR from the following equation.

$$
\mathrm{CVR}=(\mathrm{MABP}-\mathrm{ICP}) / \mathrm{mCBF} 100 \mathrm{gm} \cdot
$$

where MABP is the mean arterial blood pressure and $\mathrm{mCBF} 100 \mathrm{gm}$ is the mCBF per $100 \mathrm{gm}$ brain. CVC can be determined from the following equation.

$$
\begin{aligned}
\mathrm{CVC}= & \mathrm{CVCT} / \mathrm{CVR} \\
= & \mathrm{CVCT} \cdot \mathrm{mCBF} 100 \mathrm{gm} / \mathrm{MABP} \\
& -\mathrm{ICP} \ldots \ldots \ldots \ldots \ldots \ldots \ldots
\end{aligned}
$$

where CVCT is the arterial pulsatile conduction time, i.e., the interval from the time the cardiac valve begins to open and deliver blood to the brain to the time when the blood volume reaches its maximum. CVCT is obtained from the formula CVCT $=\mathrm{CVC}$ $\times$ CVR.

Cerebral plethysmograms were obtained by applying of $300 \mu \mathrm{A}$ of electricity and observing of impedance of the stimulation of $50-\mathrm{kHz}$ sine waves.

The stainless steel, insulated, needle-type electrodes (Sanei Co.) were $0.2 \mathrm{~mm}$ in diameter and 20 $\mathrm{mm}$ in length. The stimulation electrode was placed on the midline from $3 \mathrm{~cm}$ posterior to the nasion to $3 \mathrm{~cm}$ posterior to the coronal suture. The sensing electrodes were placed within $2 \mathrm{~cm}$ of the stimulation electrodes, the anterior site being on the midline and the posterior site being on a diagonal line drawn $45^{\circ}$ from the midline. The electrodes were inserted percutaneously as far as the cranium (Fig. 1).

In plethysmograms, the peak-to-peak amplitude of respiratory cerebral movement is designated $\Delta \mathrm{R}$, and the peak-to-peak amplitude of arterial pulsatile movement in the first peak of respiratory change is $\triangle \mathrm{Pa}$. Although CVCT is the interval from the opening of the aortic valve to the point of peak cerebral blood volume, for simplicity we used instead the interval from closure of the tricuspid valve (the $R$ wave on electrocardiograms ${ }^{4)}$ ) to the point of peak arterial pulsatile cerebral movement. In four of the eight

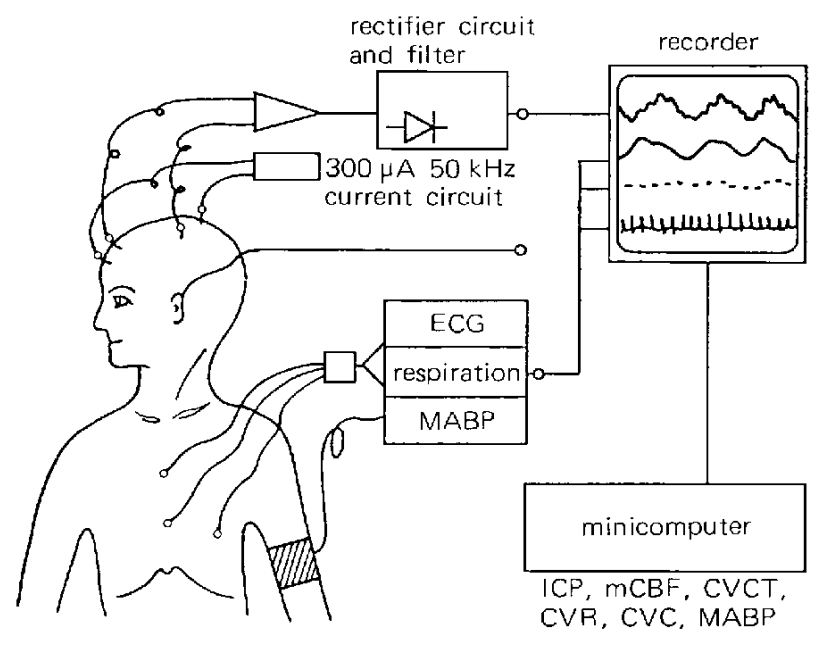

Fig. 1 Skull impedance plethysmographic monitoring system. ECG: electrocardiography, MABP: mean arterial blood pressure, ICP: intracranial pressure, $\mathrm{mCBF}$ : mean cerebral blood flow, CVCT: cerebrovascular conduction time, CVR: cerebrovascular resistance, CVC: cerebrovascular compliance. 


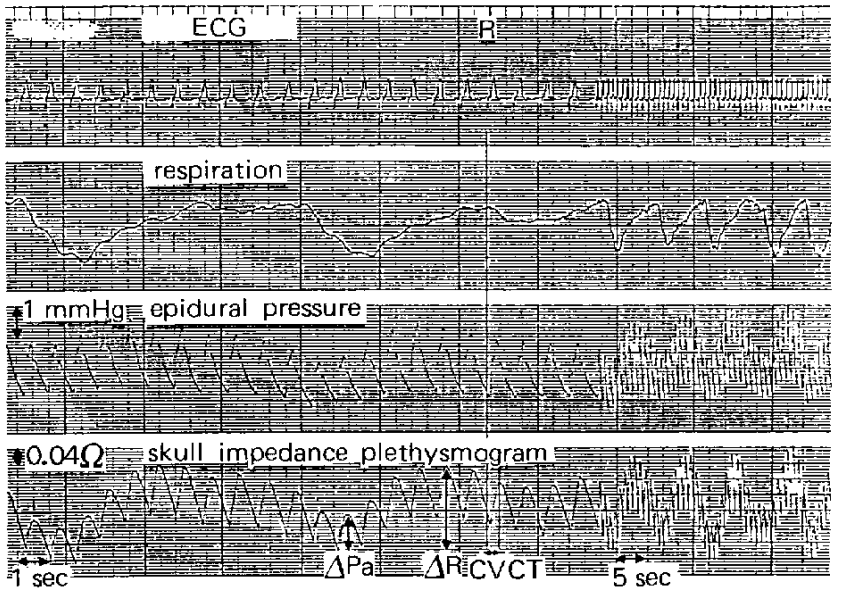

Fig. 2 Postoperative skull impedance plethysmogram and other monitoring readouts of a chronic subdural hematoma patient. $\triangle \mathrm{Pa}$ : arterial pulsatile cerebral movement, $\Delta \mathrm{R}$ : respiratory cerebral movement.
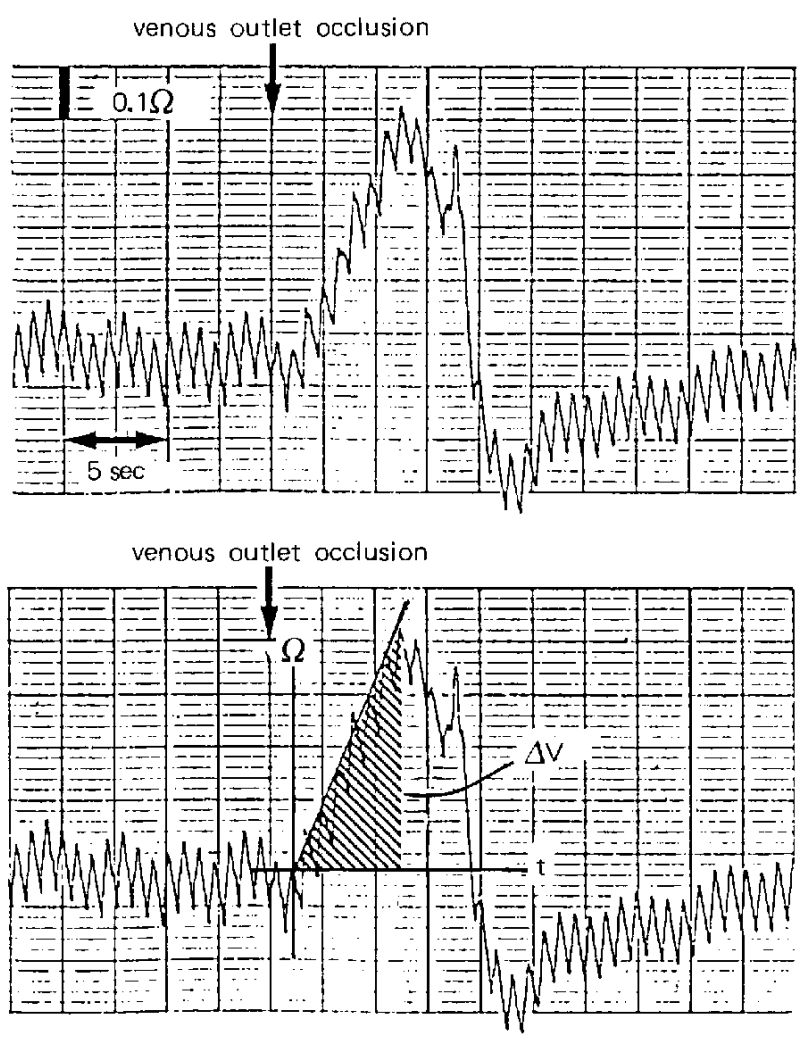

Fig. 3 Calculation of $\mathrm{mCBF}$ by venous outlet occlusion according to the equation $\mathrm{mCBF}=\mathrm{K}_{2}$. $\Delta \mathrm{V} \cdot \mathrm{t}$, using skull impedance plethysmography. upper: Original plethysmogram. lower: Calculation method. $\Delta \mathrm{V}$ : change in skull impedance plethysmogram, $\mathrm{t}: \Delta \mathrm{V}$ change time ( 5 seconds), $\mathrm{K}_{2}$ : proportionality coefficient $(=500)$. chronic subdural hematoma patients, an epidural pressure monitoring sensor (Unique Medical Co.) was fitted over the epidural space of the ipsilateral cerebral hemisphere so that pressure and impedance data could be compared. Electrocardiographic and respiratory waves were recorded concurrently and continuously in all cases (Fig. 2). The changes in skull impedance $(\Delta \mathrm{V})$ for 5 seconds following simultaneous manual occlusion of both jugular veins were determined for calculation of $\mathrm{mCBF}$ according to equation $\mathrm{II}^{10,11,22)}$ (Fig. 3).

\section{Results}

The skull impedance plethysmograms of normal adults clearly demonstrated respiratory and pulsatile cerebral movements. The change in the former was $0.16-0.24 \Omega$, and in the latter $0.03-0.08 \Omega$. According to equation I, ICP was $9.3 \pm 5.30 \mathrm{mmHg}$ (mean \pm $\mathrm{SD}$ ). The $\mathrm{mCBF}$ was $701.0 \pm 79.60 \Omega \cdot \mathrm{sec}$ (equation II). Therefore, according to equation III, CVR was determined to be $1.9 \pm 0.59 \mathrm{mmHg} \cdot \mathrm{ml} / 100 \mathrm{gm} /$ $\mathrm{min}^{-1}$. The CVCT was $0.42 \pm 0.072 \mathrm{sec}$, so that $\mathrm{CVC}$, as calculated with equation IV, was $0.22 \pm$ $0.094 \mathrm{sec} \cdot \mathrm{ml} / 100 \mathrm{gm} / \mathrm{min} \cdot \mathrm{mmHg}^{-1}$. The CPP was $89.2 \pm 5.41 \mathrm{mmHg}$.

The mean values calculated from the preoperative plethysmograms of the chronic subdural hematoma patients were: ICP, $27.3 \pm 6.8 \mathrm{mmHg}$; $\mathrm{mCBF}$, $498.22 \pm 59.59 \Omega \cdot \mathrm{sec} ; \mathrm{CVR}, 2.2 \pm 0.42 \mathrm{mmHg} \cdot \mathrm{ml} /$ $100 \mathrm{gm} / \mathrm{min}^{-1}$; CVCT, $0.39 \pm 0.071 \mathrm{sec}$; CVC, 0.19 $\pm 0.081 \mathrm{sec} \cdot \mathrm{ml} / 100 \mathrm{gm} / \mathrm{min} \cdot \mathrm{mmHg}^{-1}$; and $\mathrm{CPP}$, $79.8 \pm 5.95 \mathrm{mmHg}$. Thus, relative to the normal values, ICP increased from 9.3 to 27.3 and CVR from 1.9 to 2.2 , while mCBF decreased from 701 to 498.22 , CVC from 0.22 to 0.19 , and CVCT from 0.42 to 0.39 (Table 1 ). Furthermore, among the patients who responded well to surgery, mean preoperative ICP was $11.4 \mathrm{mmHg}$ lower than that of the poor responders, while $\mathrm{mCBF}$ and $\mathrm{CPP}$ were higher by $39.6 \Omega \cdot \mathrm{sec}$ and $6.6 \mathrm{mmHg}$, respectively. For this reason, $\mathrm{CVC}$ was higher by $0.01 \mathrm{sec} \cdot \mathrm{ml} / 100 \mathrm{gm} /$ $\mathrm{min} \cdot \mathrm{mmHg}^{-1}$ and CVCT was longer by $0.04 \mathrm{sec}$ in the good responders (Table 2).

After 5-minute inhalation of $3 \% \mathrm{CO}_{2}, \mathrm{mCBF}$ in the good responders increased by an average of $106.7 \%$. Five of these six patients $(83 \%)$ showed a change of more than $50 \%$, compared with a mean increase of only $44.5 \%$ in the poor responders (Fig. 4). In addition, the mean CVC and CVR of the good responders increased by $101.5 \%$ and decreased by $41.8 \%$, respectively, whereas those of the poor responders increased by only $46.5 \%$ and decreased by only $27.5 \%$, respectively. In operation effective 
Table 1 Skull impedance plethysmographic data of normal adult and preoperative chronic subdural hematoma patients

\begin{tabular}{|c|c|c|}
\hline & $\begin{array}{c}\text { Normal } \\
\text { adults } \\
\text { (mean } \pm \mathrm{SD} \text { ) }\end{array}$ & $\begin{array}{c}\text { Chronic } \\
\text { subdural } \\
\text { hematoma } \\
\text { patients } \\
\text { (mean } \pm \mathrm{SD} \text { ) }\end{array}$ \\
\hline $\begin{array}{l}\text { Intracranial pressure } \\
(\mathrm{mmHg})\end{array}$ & $9.3 \pm 5.30$ & $27.3 \pm 6.8$ \\
\hline $\begin{array}{l}\text { Cerebral perfusion } \\
\text { pressure (mmHg) }\end{array}$ & $89.2 \pm 5.41$ & $79.8 \pm 5.95$ \\
\hline $\begin{array}{l}\text { Mean cerebral blood } \\
\text { flow }(\Omega \cdot \mathrm{sec})\end{array}$ & $701.0 \pm 79.60$ & $498.2 \pm 59.59$ \\
\hline $\begin{array}{l}\text { Cerebrovascular } \\
\text { resistance } \\
(\mathrm{mmHg} \cdot \mathrm{ml} / 100 \mathrm{gm} / \\
\left.\min ^{-1}\right)\end{array}$ & $1.9 \pm 0.59$ & $2.2 \pm 0.42$ \\
\hline $\begin{array}{l}\text { Cerebrovascular } \\
\text { compliance } \\
(\mathrm{sec} \cdot \mathrm{ml} / 100 \mathrm{gm} / \\
\left.\mathrm{min} \cdot \mathrm{mmHg} \mathrm{Hg}^{-1}\right)\end{array}$ & $0.22 \pm 0.094$ & $0.19 \pm 0.081$ \\
\hline $\begin{array}{l}\text { Cerebrovascular } \\
\text { conduction time (sec) }\end{array}$ & $0.42 \pm 0.072$ & $0.39 \pm 0.071$ \\
\hline
\end{tabular}

Table 2 Preoperative skull impedance plethysmographic data of good $(n=6)$ and poor $(n=2)$ responders to surgery

\begin{tabular}{|c|c|c|}
\hline & $\begin{array}{l}\text { Good responders } \\
\quad(\text { mean } \pm S D)\end{array}$ & $\begin{array}{c}\text { Poor } \\
\text { responders } \\
(\text { mean } \pm S D)\end{array}$ \\
\hline $\begin{array}{l}\text { Intracranial pressure } \\
(\mathrm{mmHg})\end{array}$ & $21.6 \pm 8.01$ & $33.0 \pm 5.6$ \\
\hline $\begin{array}{l}\text { Cerebral perfusion } \\
\text { pressure (mmHg) }\end{array}$ & $83.1 \pm 6.12$ & $76.5 \pm 5.77$ \\
\hline $\begin{array}{l}\text { Mean cerebral blood } \\
\text { flow }(\Omega \cdot \mathrm{sec})\end{array}$ & $518.03 \pm 62.28$ & $478.4 \pm 56.89$ \\
\hline $\begin{array}{l}\text { Cerebrovascular } \\
\text { resistance } \\
\left(\mathrm{mmHg}^{-1} \mathrm{ml} / 100 \mathrm{gm} /\right. \\
\left.\min ^{-1}\right)\end{array}$ & $2.3 \pm 0.33$ & $2.1 \pm 0.51$ \\
\hline $\begin{array}{l}\text { Cerebrovascular } \\
\text { compliance } \\
(\mathrm{sec} \cdot \mathrm{ml} / 100 \mathrm{gm} / \\
\left.\mathrm{min} \cdot \mathrm{mmHg} \mathrm{Hg}^{-\mathrm{T}}\right)\end{array}$ & $0.19 \pm 0.077$ & $0.18 \pm 0.084$ \\
\hline $\begin{array}{l}\text { Cerebrovascular } \\
\text { conduction time (sec) }\end{array}$ & $0.41 \pm 0.059$ & $0.37 \pm 0.082$ \\
\hline
\end{tabular}

group, in particular, four of six cases (67\%) showed more than $50 \%$ changes (Fig. 5). These results indicate that, in patients who respond favorably to surgery, preoperative cerebrovascular reactivity to inhaled $\mathrm{CO}_{2}$ is high.

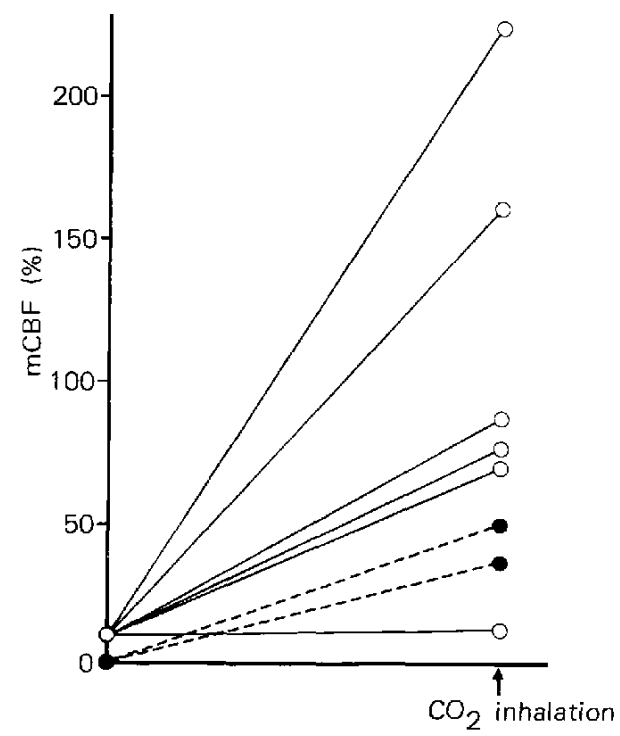

Fig. 4 Cerebrovascular reactivity of $\mathrm{mCBF}$ to 5 minute inhalation of $3 \% \mathrm{CO}_{2}$ in chronic subdural hematoma patients. $O$ : good responders $(n=6), \bullet:$ poor responders $(n=2)$.

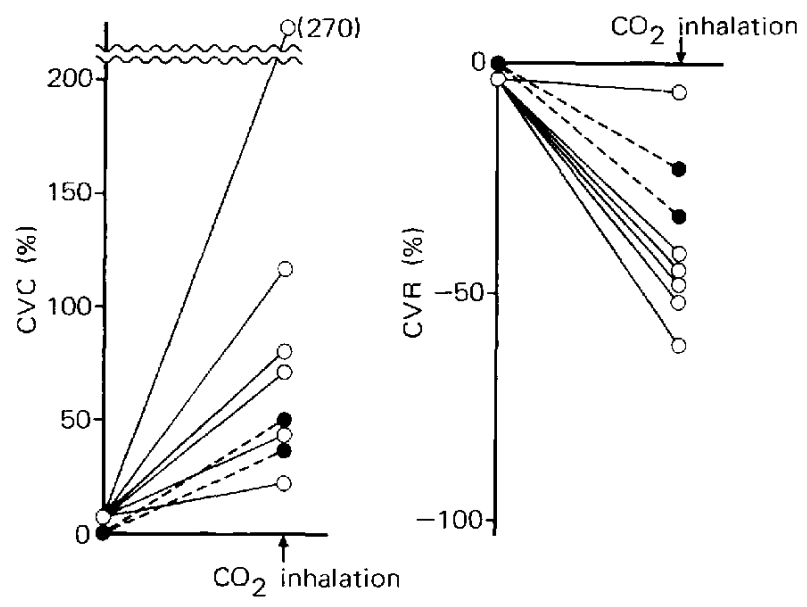

Fig. 5 Reactivity of CVC and CVR to 5-minute inhalation of $3 \% \mathrm{CO}_{2}$ in chronic subdural hematoma patients. $O$ : good responders $(n=6)$, - : poor responders $(\mathrm{n}=2)$.

\section{Representative cases}

Case 1: This patient responded well to surgery and, as shown in Fig. 6, the preoperative skull impedance plethysmogram showed an ICP of 21.6 $\mathrm{mmHg}$. Upon inhalation of $\mathrm{CO}_{2}, \mathrm{mCBF}$ increased by $53.1 \%$. With this improvement, CVR decreased by $23.8 \%$, while CVC increased by $62.5 \%$, reflecting very good cerebrovascular reactivity. After removal of the hematoma, CT disclosed a marked decrease of 
hematoma space. Postoperative ICP decreased by $10.5 \mathrm{mmHg}$ and $\mathrm{mCBF}$ increased substantially. Skull impedance plethysmography also showed an increase in pulsatile and respiratory wave form changes.

Case 2: This patient, whose clinical data are given in Fig. 7, also improved after surgery. The preoperative skull impedance plethysmogram demonstrated an ICP of $15 \mathrm{mmHg}$. Inhalation of $\mathrm{CO}_{2}$ produced a marked increase in $\mathrm{mCBF}(228.6 \%)$, along with a decrease in CVR of $70.6 \%$ and an increase in CVC

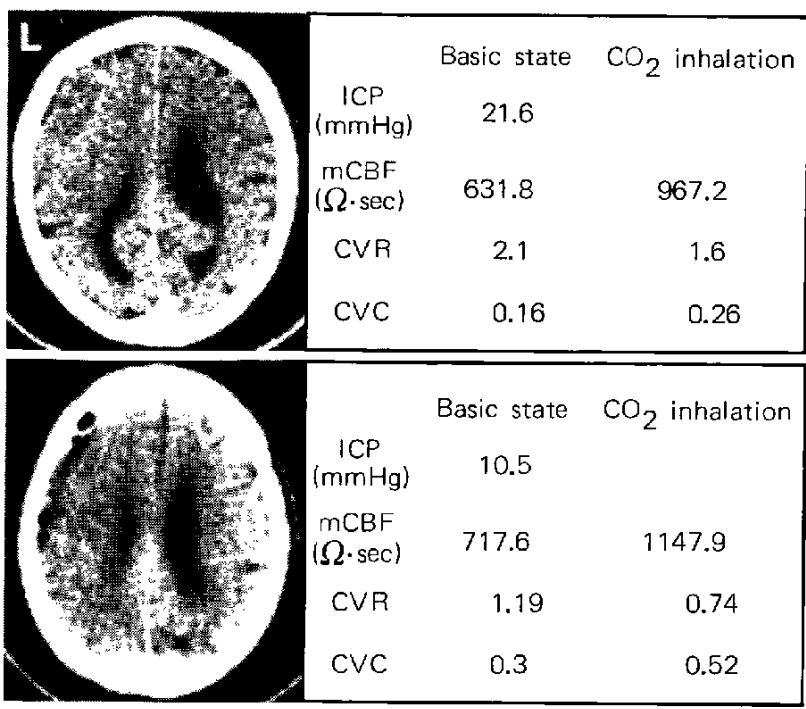

Fig. 6 Case 1. Pre-(upper) and postoperative (lower) skull impedance plethysmographic data.

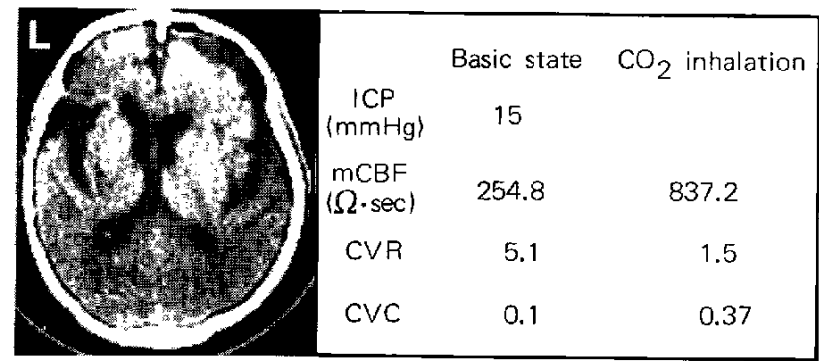

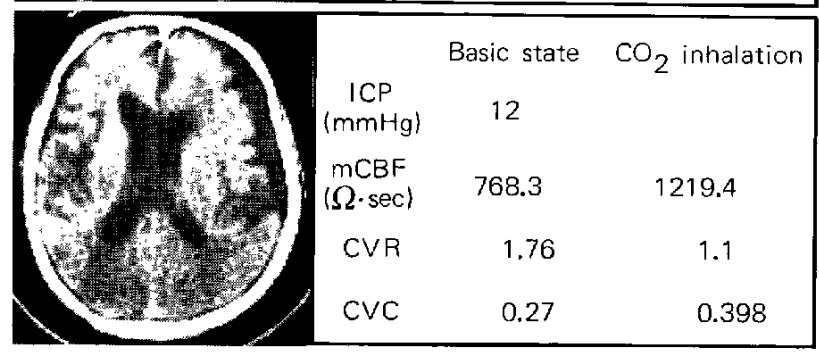

Fig. 7 Case 2. Pre-(upper) and postoperative (lower) skull impedance plethysmographic data.

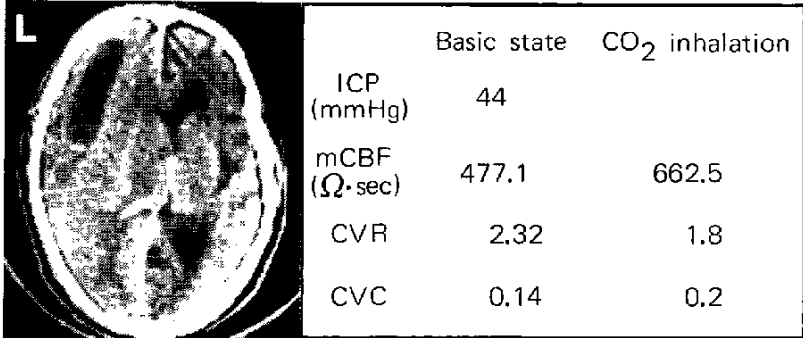

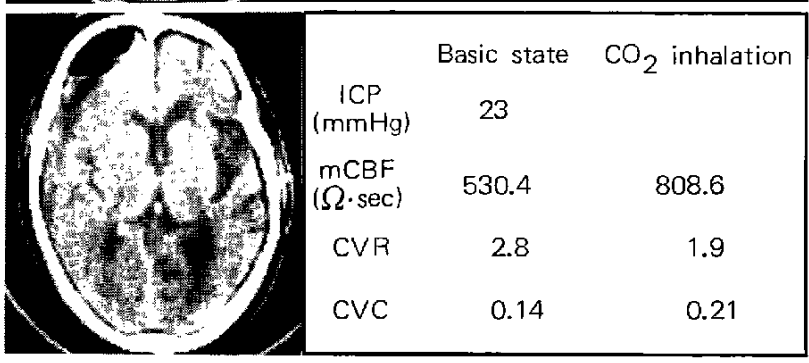

Fig. 8 Case 3. Pre- (upper) and postoperative (lower) skull impedance plethysmographic data.

of $270 \%$. As in Case 1 , these changes are indicative of good cerebrovascular reactivity. Despite little reduction of the hematoma space, as shown by postoperative CT, this patient's neurological symptoms improved dramatically and $\mathrm{mCBF}$ increased significantly.

Case 3: As the data in Fig. 8 show, this patient had a poor response to surgery. Preoperative skull impedance plethysmography disclosed an abnormally high ICP of $44 \mathrm{mmHg}$. $\mathrm{CO}_{2}$ intralation raised the mCBF by only $38.9 \%$, decreased CVR by only $22 \%$, and increased $\mathrm{CVC}$ by a mere $42.9 \%$. On postoperative $\mathrm{CT}$, reduction of the hematoma space was slight and $\mathrm{mCBF}$ showed only a small increase.

\section{Discussion}

Several factors reportedly contribute to the postoperative prognosis for patients with symptomatic chronic subdural hematoma. Advanced age and the presence of other serious disease are said to compromise the probability of neurological recovery. ${ }^{6,17-19,23,25)}$ Regarding the significance of focal symptoms, Tsuboi et al. ${ }^{23)}$ emphasized mental manifestations, citing dementia as a particularly unfavorable prognostic indicator.

Ikeda et $a l .{ }^{14)}$ found that postoperative recovery was poor in patients in whom the appearance of mental symptoms was delayed (average, $90 \pm 23$ days), particularly in cases involving dementia. Takahashi et al. ${ }^{20)}$ proposed that surgery should be performed before focal symptoms appear. The 
available data indicate that the longer the interval between trauma (or onset of symptoms) and surgery, the worse the prognosis, and several investigators ${ }^{14,19,23)}$ have asserted that the prognosis is very poor if the interval exceeds 2 weeks. In terms of CT findings, it has been noted that when low density within the hematoma space, cerebral atrophy, and signs of cerebral compression (smooth cerebral surface, disappearance of cerebral sulci, and surrounding mass effect) are insignificant, the lag between trauma and onset of symptoms is generally longer, and postoperative regression of the hematoma space tends to be delayed and neurological symptoms tend to persist. ${ }^{13,19,20)}$ In the present study, recovery of neurological symptoms was not always correlated with CT evidence of disappearance of the hematoma space, an observation made also by Nishijima et al. ${ }^{19)}$

Regarding physiological factors, Ikeda et $a l^{14)}$ reported that critical CBF at the appearance of symptoms averaged $40 \mathrm{ml} / 100 \mathrm{gm} / \mathrm{min}$ (approximately $500 \mathrm{ml} / \mathrm{min}$ ), and recommended that surgery be performed when this value reaches $25 \mathrm{ml} / 100 \mathrm{gm} / \mathrm{min}$ (approximately $300 \mathrm{ml} / \mathrm{min}$ ) or higher. The critical point referred to by these investigators is in good agreement with the preoperative $\mathrm{mCBF}$ of chronic subdural hematoma patients in our study. Tsubokawa et al. ${ }^{24)}$ used bolus manipulation to determine the intracranial pressure/volume relationship, from which the fit of the cranium to the brain and thus the status of the hematoma space can be determined, and reported a significant difference between patients for whom surgery was effective and those for whom it was ineffective.

We previously described skull impedance plethysmography ${ }^{10,11,221}$ as a noninvasive method to assess the cerebrovasculature, which plays an important role in brain pathophysiology.

CBF decreases when ICP exceeds a cerebral capillary pressure of $30-40 \mathrm{mmHg}$, and the intercompartmental pressure difference within the cranium causes a shift leading to cerebral herniation. ${ }^{3,8,9,15,16,21)}$ These events eventually alter cerebral metabolism, cerebral water and blood contents, and cerebrovascular reactivity. Therefore, cerebral pathology cannot be fully assessed merely by measuring ICP. The fact that impedance plethysmography registers volume changes in the organic blood volume was first reported in 1972 by Geddes and Baker, ${ }^{7}$ and this was confirmed by Anderson $e t$ $a l^{1,2,12)}$ Using this plethysmographic method, we have made it possible, for the first time, to measure not only ICP but also CBF, CVR, and CVC simultaneously without resorting to surgical procedures.

As compared with normal adults, whose mean
$\mathrm{mCBF}$ was $701.0 \pm 79.6 \Omega \cdot \mathrm{sec}$, the $\mathrm{mCBF}$ of chronic subdural hematoma patients was much lower $-498.22 \pm 59.59 \Omega \cdot \mathrm{sec}$ - which is in good agreement with the critical point for the onset of symptoms $(40 \mathrm{ml} / 100 \mathrm{gm} / \mathrm{min}$, or $500 \mathrm{ml} / \mathrm{min})$ reported by Ikeda et al. ${ }^{14)}$ Taking ICP, CVC, CVCT, CVR, and CPP into consideration, it is apparent that $\mathrm{mCBF}$ decreased as ICP rose, leading to an increase in CPP and disturbance of the capillary system, which is driven by pulsative active energy. This in turn led to an increase in CVR and a decrease in CVC, causing the cerebrovascular system to become a system with rigid pipes. ${ }^{15,16)}$ In addition to disturbed compensatory mechanisms of the brain, CVCT had probably been shortened.

When the patients who responded well to surgery were compared with those who responded poorly, a significant difference was observed in cerebral reactivity to 5 -minute inhalation of $3 \% \mathrm{CO}_{2}$. In the good responders, $\mathrm{mCBF}$ increased by $106.7 \%$ on the average, and five of six patients in this group had increases of $50 \%$ or more. Their mean CVC also increased by $101.5 \%$, with four of six patients showing increases of $50 \%$ or more. On the other hand, the poor responders showed a mean increase of only $44.5 \%$ in $\mathrm{mCBF}$ and $46.5 \%$ in CVC. Thus, it was clear that cerebrovascular reactivity to inhalation of $\mathrm{CO}_{2}$ was greater in the good responders than in the poor responders. Considering these results and those of Tsubokawa et al. ${ }^{24)}$ it appears that preoperative intracranial compliance, including the cerebrovascular system, is better in good responders than in poor responders.

Since the skull impedance plethysmographic method we used in this study measures cerebral volume on the basis of fluctuations in electrical resistance due to changing cerebral blood volume, errors in measurement can occur, depending on the position of the sensors on the scalp and on the size of the cranium. Therefore, in the clinical application of this method, there may be difficulty in utilizing the experimental proportionality coefficients. However, if the measured volumes are used not as direct indices but as indices of ratio of change, this method can be applied clinically. It is our intention to continue clinical investigations using this method.

\section{References}

1) Anderson FA, Peura RA, Penney WC, Hoffman AH, Wheeler HB: Simultaneous mechanical and electrical impedance plethysmography. Proc 2nd Ann New Engl Bioengng Conf. 1974, pp 161-167, cited in 12)

2) Anderson FA Jr, Peura RA, Penney BC, Wheeler HB: 
Comparison of electrical impedance and mechanical plethysmographic techniques in the human calf. Proc Ass Adv Med Instrum (Annual Meeting). 1977, p 281 , cited in 12)

3) Brock M, Furuse M, Weber R, Hasuo M, Dietz $\mathrm{H}$ : Brain tissue pressure gradients, in Lundberg $\mathrm{N}$, Ponteu U, Brock M (eds): Intracranial Pressure. Berlin, Springer, 1975, pp 215-220

4) Caro CG, Pedly TJ, Schroter RC, Seed WA: The Mechanics of the Circulation: The Cardiac Cycle. New York, Oxford University, 1978, pp 186-190

5) Cooke RWI, Rolfe P: Cerebral blood flow measurement using venous occlusion plethysmography in the newborn human infant, in Rolfe $\mathrm{P}(e d)$ : Noninvasive Physiological Measurements, vol 1. New York, Academic, pp 175-191

6) Fogelholm $\mathrm{R}$, Heiskanen $\mathrm{O}$, Waltimo $\mathrm{O}$ : Chronic subdural hematoma in adults: Influence of patient's age on symptoms, signs, and thickness of hematoma. $J$ Neurosurg 42: 43-46, 1975

7) Geddes LE, Baker LE: Thoracic impedance changes following saline injection into right and left ventricles. J Appl Physiol 33: 278-281, 1972

8) Hayashi N, Takeuchi T: Cerebral tissue circulation and cerebral venous circulation, in Takeuchi $\mathrm{T}(e d)$ : Circulation -Pathophysiology, Diagnosis and Therapy, ed 1. Tokyo, Bunko-do, 1980, pp 295-323 (in Japanese)

9) Hayashi $\mathrm{N}$, Takeuchi $\mathrm{T}$, Sugawara $\mathrm{T}$, Goto $\mathrm{T}$, Tsubokawa $T$, Moriyasu N: The alteration of perfusion pressure and cerebral circulation during intracranial hypertension caused by inflation of balloons in the infra- and supratentorial spaces. Neurol Med Chir (Tokyo) 16[Part I1]: 515-523, 1976 (in Japanese)

10) Hayashi $N$, Tsubokawa $T$, Kimura S, Makiyama $Y$, Kushi H: Noninvasive monitoring of cerebral circulation, oxygen metabolism and intracranial pressure using laser. Nippon Laser Igakkai Shi 6: 331-334, 1986 (in Japanese)

11) Hayashi N, Tsubokawa $T$, Takeuchi $T$, Kushi $H$, Kimura S, Makiyama Y, Matsumura A: Noninvasive evaluations of intracranial pressure, cerebral blood flow, vascular compliance and oxygen consumption using laser infrared spectroanalysis and the skull impedance plethysmographic method, in Miller JD, Teasdale GM, Rowan JO, Galbraith SL, Mendelow AD (eds): Intracranial Pressure, vol VI. New York, Springer, 1985, pp 235-239

12) Hill DW: The role of electrical impedance methods for the monitoring of central and peripheral blood flow changes, in Rolfe $\mathrm{P}$ (ed): Non-invasive Physiological Measurements, vol I. New York, Academic, pp 95-110

13) Hyodo A, Nose T, Enomoto T, Maki Y: Chronic subdural hematoma. Changed its density from low to high on follow-up CT. No Shinkei Geka 8: 649-653, 1980 (in Japanese)

14) Ikeda $\mathrm{K}$, Itoh $\mathrm{H}$, Yamamoto $\mathrm{S}$ : Relation between symptoms of chronic subdural hematoma and hematoma volume or regional cerebral blood flow. Program of the 42th Congress of the Japan Neurosurgical Society. 1982, p 60

15) Langfitt TW, Weinstein JD, Kassel NF: Cerebral vasomotor paralysis produced by intracranial hypertension. Neurology (Minneap) 15: 622-641, 1965

16) Langfitt TW, Weinstein JD, Kassel NF, Simeone FA: Transmission of increased intracranial pressure. I. Within the craniospinal axis. J Neurosurg 21: 989997,1964

17) Luxton LM, Harrison MJB: Chronic subdural hematoma. $Q J \mathrm{Med}$ 189: 43-53, 1979

18) Nakamura N, Ogawa $T$, Hashimoto $T$, Yuki $K$, Kobayashi S: Reevaluation on resolving subdural hematoma. Neurol Med Chir (Tokyo) 21: 491-500, 1981 (in Japanese)

19) Nishijima M, Horie $Y$, Nakata J, Oka N, Endo S, Takaku A: Postoperative regression of chronic subdural hematoma. Sequential study by computed tomography. No Shinkei Geka 11: 813-819, 1983 (in Japanese)

20) Takahashi Y, Mikami J, Sato H, Takeda S, Mitsuoka T, Ito K, Ueda M, Ohkawara S: Analysis of chronic subdural hematoma based on CT (Part 2). Symptoms and CT findings. Neurol Med Chir (Tokyo) 22: 395-401, 1982 (in Japanese)

21) Takeuchi $\mathrm{T}$ : Alteration of tissue fluid pressure and perfusion pressure during intracranial hypertension. $J$ Nihon Univ Med Ass 35: 817-839, 1976 (in Japanese)

22) Takeuchi $\mathbf{T}$, Kimura $S$, Kushi H, Hayashi $\mathbf{N}$, Tsubokawa T: Development of cerebral blood flow measurement using skull impedance plethysmography. No Shinkei Geka 14: 1439-1445, 1986 (in Japanese)

23) Tsuboi K, Maki Y, Nose T, Matsuki T: Psychiatric symptoms of patients with chronic subdural hematoma. No Shinkei Geka 12: 275-279, 1984 (in Japanese)

24) Tsubokawa $T$, Doi $N$, Ohata $H$, Yoshida $K$ : Pressure/volume relationship as postoperative prognostic index. Journal of Intracranial Pressure 1: 912,1984

25) Yamamoto S: Chronic subdural hematoma. Neurol Med Chir (Tokyo) 19: 401-409, 1979 (in Japanese)

Address reprint requests to: T. Takeuchi, M.D., Neurosurgical Department, The Municipal of Higashimatsuyama Hospital, 2392 Matsuyama, Higashimatsuyama, Saitama 355, Japan. 